\title{
Safety of Consecutive Bilateral Decubitus Digital Subtraction Myelography in Patients with Spontaneous Intracranial Hypotension and Occult CSF Leak
}

\author{
(D) M.C. Pope, (DC.M. Carr, (D). Brinjikji, and DD.K. Kim
}

\begin{abstract}
BACKGROUND AND PURPOSE: Digital subtraction myelography performed with the patient in the lateral decubitus position has the potential for increased sensitivity over prone-position myelography in the detection of spinal CSF-venous fistulas, a well-established cause of spontaneous intracranial hypotension. We report on the safety of performing routine, consecutive-day right and left lateral decubitus digital subtraction myelography in these patients.
\end{abstract}

MATERIALS AND METHODS: In this retrospective case series, all patients undergoing consecutive-day lateral decubitus digital subtraction myelography for suspected spinal CSF leak between September 2018 and September 2019 were identified. Chart review was performed to identify any immediate or delayed adverse effects associated with the procedures. Procedural parameters were also analyzed due to inherent variations associated with the positive-pressure myelography technique that was used.

RESULTS: A total of 60 patients underwent 68 pairs of consecutive-day lateral decubitus digital subtraction myelographic examinations during the study period. No major adverse effects were recorded. Various minor adverse effects were observed, including pain requiring analgesics (27.2\%), nausea/vomiting requiring antiemetics (8.1\%), and transient neurologic effects such as syncope, vertigo, altered mental status, and autonomic dysfunction (5.1\%). Minor transient neurologic effects were correlated with increasing volumes of intrathecal saline injectate used for thecal sac prepressurization.

CONCLUSIONS: In patients with spontaneous intracranial hypotension and suspected spontaneous spinal CSF leak, consecutive-day lateral decubitus digital subtraction myelography demonstrates an acceptable risk profile without evidence of neurotoxic effects from cumulative intrathecal contrast doses. Higher intrathecal saline injectate volumes may correlate with an increased incidence of minor transient periprocedural neurologic effects.

ABBREVIATIONS: DSM = digital subtraction myelography; $\mathrm{SIH}=$ spontaneous intracranial hypotension

$\mathrm{S}$ pontaneous intracranial hypotension (SIH) is a syndrome of orthostatic headaches and other potentially debilitating neurologic symptoms attributable to spontaneous spinal CSF leaks. ${ }^{1,2}$ Distinct subtypes of spinal CSF leaks have been described, including dural tears and CSF-venous fistulas along the nerve root sleeves. Ventral dural tears are often associated with epidural fluid collections, which can be longitudinally extensive along the spinal axis. ${ }^{3,4}$ These leaks usually are well-characterized by conventional spinal MR imaging and $\mathrm{CT}$ or MR myelography. Conversely, CSF-venous fistulas and some nerve root sleeve dural tears may present without identifiable extradural fluid collections. ${ }^{5-7}$ Adjunctive techniques such as dynamic CT myelography

Received March 23, 2020; accepted after revision July 1.

From the Department of Radiology, Mayo Clinic, Rochester, Minnesota.

Please address correspondence to Matthew C. Pope, Mayo Clinic, 200 First St SW, Rochester, MN 55905; e-mail: Pope.matthew@mayo.edu

http://dx.doi.org/10.3174/ajnr.A6765 and digital subtraction myelography (DSM) can be used to increase the sensitivity for these occult leaks and provide precise localization for subsequent surgical repair or blood patching. ${ }^{8-11}$

In particular, digital subtraction myelography has proved effective for detecting occult CSF leaks due to its superior spatial and temporal resolution. ${ }^{9,12}$ Various procedural variations have recently been described in the literature, most notably the performance of DSM imaging with the patient in the lateral decubitus position. Schievink et $\mathrm{al}^{13}$ demonstrated a 5 -fold increase in the detection rate of previously occult CSF-venous fistulas by performing DSM with patients in the lateral decubitus position instead of conventional prone positioning. Farb et $\mathrm{al}^{5}$ also reported success with the lateral decubitus DSM technique in detecting spinal CSF-venous fistulas as well as a case of nerve root sleeve dural tear.

At our institution, right and left lateral decubitus DSM was typically performed on consecutive days for patients being evaluated for SIH without an identifiable CSF leak on prior MR 
imaging and/or conventional CT myelography. This approach provided several advantages over targeted or unilateral DSM. For example, performing a comprehensive bilateral decubitus DSM examination with accompanying decubitus CT myelography within a 24-hour window was less burdensome for our patients, simplifying scheduling and potentially reducing travel expense. This also ensured that no multifocal bilateral leaks were overlooked.

While the relative safety of intrathecal iodinated contrast and various lumbar puncture techniques for myelography has been well-documented, ${ }^{14-19}$ the risk profile of performing consecutive myelographic procedures as discussed above has not been previously described. Specifically, there are currently no data on the potential for increased adverse effects related to a cumulative intrathecal iodinated contrast load within such a short timeframe. Additional considerations include increased patient exposure to radiation, sedation, and general procedural risk. We report on our experience with this unique practice during a 13-month period.

\section{MATERIALS AND METHODS \\ Study Cohort}

In this single-institution retrospective case series, we identified all patients with SIH undergoing lateral decubitus DSM to evaluate occult CSF leaks between September 2018 and September 2019. Inclusion criteria were the following: 1) clinical suspicion of $\mathrm{SIH}$ based on evaluation by neurologists with subspecialty experience in CSF dynamics disorders; 2) prior brain and spinal MR imaging deemed inconclusive for definitive spinal CSF leak; and 3) the availability of intraprocedural and postprocedural care documentation in the electronic medical record. Given our primary concern with cumulative effects of consecutive-day procedures, any lateral decubitus DSM procedures performed on 1 side only or bilaterally on nonconsecutive days were excluded. These were generally in the case of patient scheduling exceptions or repeat examinations due to extradural injections on the initial procedure.

\section{Procedural Technique}

Lateral decubitus DSM procedures were conducted per our recently described technique. ${ }^{20}$ All examinations were performed by a core group of 10 subspecialty neuroradiologists who received training from a single individual. Because this was a new procedure for our institution, some changes to the protocol were made early in the study period. For example, Omnipaque 240 (iohexol; GE Healthcare) was the intrathecal contrast agent used initially, but Omnipaque 300 was subsequently found to produce higher quality images due to higher concentration and became the agent of choice for most cases in the study group. Additionally, varying amounts of sterile preservative-free normal saline (Baxter) were injected before main contrast runs in an attempt to create positive intrathecal pressure and facilitate a CSF leak, which can be intermittent, thereby improving detection of the leak. ${ }^{21,22}$ The volume of saline injected was variable and ultimately based on operator preference. Both 20- and 22-ga Quincke spinal needles (Becton Dickinson) were used, and this was also based on operator preference and consideration of factors such as patient body habitus. Imaging was performed with Allura Xper FD 20/20 (Philips Healthcare) or Axion Artis dTA ceiling-mounted (Siemens) systems. Procedures were intended to be performed 24 hours apart, though in practice, the time interval in a small number of cases was as short as 19 hours or as long as 28 hours.

\section{Data Collection}

Retrospective chart review of procedure reports, clinical notes, medication administration logs, and radiation logs within the institutional electronic medical record was performed to identify relevant periprocedural data. In addition to demographic data, the following variables were recorded for each DSM procedure: spinal level accessed (L1-L5), needle gauge (20- versus 22-ga), volume of intrathecal contrast injectate (milliliters), volume of intrathecal saline injectate (milliliters), type of intrathecal contrast material (Omnipaque 240 or Omnipaque 300), total fluoroscopy time (seconds), and total radiation skin dose (milligray). Radiation dose parameters were obtained from the automated software recording on the angiographic equipment. The type of anesthesia (local, moderate, or general) was also recorded, given the potential for confounding of documented adverse effects. All postprocedural clinical encounters were reviewed for documentation of delayed adverse effects, extending to 3 months after the conclusion of the study period. If a leak was identified and subsequent definitive treatment with spinal surgery or intrathecal blood patching was performed, these steps were considered an end point due to potential confounding as to the source of the adverse effect.

\section{Adverse Effects}

Adverse effects were classified as major or minor. Major adverse effects included procedure-site infections, procedure-site bleeding requiring intervention, acute radiation injury, or a variety of major, rare neurotoxic effects classically associated with intrathecal iodinated contrast such as seizures, arachnoiditis, and longterm mental status changes. ${ }^{23}$ Minor adverse effects included intraprocedural and immediate postprocedural complications such as pain (for example, headache, backache, or leg pain) or nausea/vomiting. Specifically, pain and nausea/vomiting were recorded if analgesic or antiemetic medication was administered and symptoms resolved within 24 hours. Any other transient neurologic symptoms such as vertigo were also categorized as minor, in keeping with the spectrum of effects seen in prior studies of iodinated contrast myelography. ${ }^{14-19}$ Adverse effects were documented either in the procedure report or periprocedural nursing logs including standardized institutional pain and Richmond Agitation Sedation Scale neurologic scores. Final categorization as a minor effect was contingent on complete spontaneous resolution of the effect within 24 hours. Any reported inadvertent extradural injections were also recorded.

\section{Statistics}

Descriptive statistics were performed to summarize patient demographics and general procedural factors. Mixed binomial logistic regression modeling and $\chi^{2}$ analysis were performed to evaluate any association between procedural factors and the probability of adverse effects. Any missing data points were excluded from comparative analyses. JMP, Version 14.1, (SAS Institute; 19892019) and SPSS, Version 25.0 (IBM; released 2017) were used for all statistical calculations. A $P$ value $<.05$ was considered statistically significant. 
Table 1: Number of procedures with adverse effects recorded

\begin{tabular}{lcccc}
\hline & \multicolumn{3}{c}{ No. of Procedures (\% of Total) } \\
\cline { 2 - 4 } Type & $0(0)$ & Day $\mathbf{2}(\boldsymbol{n}=\mathbf{6 8})$ & Day $\mathbf{3}(\boldsymbol{n}=136)$ & $\boldsymbol{P}$ Value \\
\hline Major adverse effect & $0(0)$ & $0(0)$ & $0(0)$ & $0(0)$ \\
Local bleeding & $0(0)$ & $0(0)$ & $0(0)$ & $0(0)$ \\
Local infection & $0(0)$ & $0(0)$ & $0(0)$ & $P=.730$ \\
Seizures & $0(0)$ & $0(0)$ & $54(39.7)$ & $P=.753$ \\
Acute radiation injury & $28(41.2)$ & $26(38.2)$ & $9(6.6)$ & $P=.335$ \\
Minor adverse effect & $5(7.4)$ & $4(5.9)$ & $11(8.1)$ & $P=.753$ \\
Subdural injection & $21(30.9)$ & $16(23.5)$ & $7(5.1)$ & $P=.698$ \\
Pain & $5(7.4)$ & $6(8.8)$ & & \\
Nausea & $3(4.4)$ & $4(5.9)$ & &
\end{tabular}

Table 2: Volume of injectate in patients experiencing transient neurologic adverse effects

\begin{tabular}{lccl}
\hline Patient & Day 1 Volume $(\mathrm{mL})$ & Day 2 Volume $(\mathrm{mL})$ & \multicolumn{1}{c}{ Symptom/Sign } \\
\hline A & 20 & $31^{\mathrm{a}}$ & Syncope \\
B & 33 & $41^{\mathrm{a}}$ & Autonomic disturbance \\
C & 26 & $41^{\mathrm{a}}$ & Altered mental status \\
D & 21 & $41^{\mathrm{a}}$ & Autonomic disturbance \\
E & $27^{\mathrm{a}}$ & 52 & Syncope \\
F & $61^{\mathrm{a}}$ & 31 & Vertigo \\
G & $43^{\mathrm{a}}$ & 33 & Altered mental status \\
\hline
\end{tabular}

${ }^{a}$ Occurrence of transient neurologic adverse effects.

Institutional review board approval with waived consent was granted for this Health Insurance Portability and Accountability Act-compliant retrospective research study.

\section{RESULTS \\ Study Cohort}

Of 151 lateral decubitus DSM procedures identified in the study period, 15 were not performed as consecutive pairs. These cases were excluded, and a total of 60 unique patients undergoing 68 pairs of consecutive lateral decubitus DSMs were evaluated. The excess procedural pairs were accounted for by 2 patients who underwent 3 separate procedural pairs each and 4 patients who underwent 2 separate procedural pairs each. These patients undergoing multiple procedural pairs generally had definitive treatment for CSF leaks after the initial study and subsequently developed recurrent symptoms meeting the inclusion criteria at least 1 month after the most recent dural puncture. The study population included $37 / 60$ women (62\%) and $23 / 60$ men (38\%) with a mean age of $54.6 \pm 11.9$ years. Chart review follow-up for a minimum of 3 months was performed in all cases, with the exception of patients undergoing targeted spinal therapy before the 3-month period ended.

\section{Procedural Parameters}

Mean contrast injectate per single procedure was $11.5 \mathrm{~mL}$, and mean saline injectate per procedure was $20.7 \mathrm{~mL}$. The mean fluoroscopy time per procedure was 8.0 minutes (median, 7.9 minutes). The average cumulative radiation exposure for each procedural pair was $666 \mathrm{mGy}$ (median, $349 \mathrm{mGy}$ ), not including subsequent CT scans, though this varied widely on the basis of patient body habitus (range, 45-2678 mGy). Lumbar punctures were performed at L3-L4 most commonly (70/136, $51.5 \%)$ followed by L2-L3 (57/136, 41.9\%), L4-L5 (7/136, 5.1\%), and L1L2 (2/136, 1.5\%). Twenty-two-gauge Quincke spinal needles were used in $73 / 136$ cases $(53.7 \%)$, and 20 -ga, in $63 / 136$ cases $(46.3 \%)$. General anesthesia was used in 71/136 cases (52.2\%); moderate sedation, in 44/136 cases (32.3\%); and local anesthesia alone, in $21 / 136$ cases $(15.5 \%)$. Omnipaque 240 was used in $18 / 136$ cases (13.2\%), and Omnipaque 300, in 118 cases (86.8\%). There were several missing data points, including saline injectate volume $(n=$ 13), fluoroscopy time $(n=1)$, and total radiation dose $(n=1)$, with the associated cases being excluded from comparative analyses.

\section{Adverse Effects}

No major adverse effects were recorded for any of the 68 procedural pairs (Table 1). A single patient with severe postprocedural vertigo, nausea, and vomiting was admitted for observation but recovered overnight and was discharged home after undergoing the second part of the procedure the following morning. An additional patient elected for overnight admission between procedures for baseline pain control. Otherwise, all procedures were performed in an outpatient setting with no major or minor adverse effects requiring admission.

Minor adverse effects were recorded in 54 of 136 total procedures (39.7\%), all of which resolved in the intraprocedural or immediate postprocedural period except as previously described (Table 1). Documented cases of pain included headache (23/136, $17.0 \%)$, backache $(2 / 136,1.5 \%)$, and leg pain $(1 / 136,0.7 \%)$. The remaining cases of pain $(11 / 136,8.1 \%)$ received a numeric score and analgesic treatment, but the location was not specified in the nursing log. The category of transient neurologic effect included cases of syncope, vertigo, altered mental status, and autonomic dysfunction (Table 2). Altered mental status included patients who briefly entered a trancelike state after intrathecal prepressurization and did not respond to verbal prompts from the proceduralist. Autonomic disturbance was used as a descriptor for 2 patients who, during general anesthesia, demonstrated transient hypertension/tachycardia and bigeminal pulse, respectively. Overall, there was no significant difference in the distribution of minor adverse effects between first- and second-day procedures.

An increased total injectate volume was noted in the patients experiencing minor transient neurologic effects. The mean injectate volume (contrast + saline) in the neurologic-effect group was $40.7 \pm 10.8 \mathrm{~mL}$, while the mean injectate volume in the remaining patients was $31.7 \pm 8.6 \mathrm{~mL}$. The mean injectate-volume variance was almost entirely accounted for by differences in saline volume used for thecal sac prepressurization because the contrast volume was constant. There was a statistically significant 
association between total injectate volume and the probability of transient neurologic effects $(P=.017)$, with no significant contributory effects from the procedure day $(P=.46)$. Injectate volume demonstrated no significant association with the probability of pain $(P=.25)$, nausea $(P=.29)$, or pooled minor adverse effects $(P=.97)$. Minor transient neurologic effects were also associated with the use of a 20 -ga spinal needle $(P=.004)$. The type of anesthesia performed was not correlated with minor neurologic effects $(P=.33)$, pain $(P=.64)$, or nausea/vomiting $(P=.21)$.

\section{DISCUSSION}

No major adverse effects were demonstrated during the 13-month study period in any of the DSM procedural pairs. The rates of minor adverse effects such as pain (27.2\%), nausea (8.1\%), and other minor transient neurologic effects (5.1\%) were comparable with complication rates in many of the original studies on lumbar myelography using iohexol. ${ }^{16-19,24,25}$ For example, Kieffer et al ${ }^{18}$ reported symptoms of headache $(21 \%)$, nausea (10\%), dizziness (3\%), and "other" symptoms (7\%), which included hypotension, paresthesia, photophobia, syncope, and somnolence. Manufacturer's studies for intrathecal Omnipaque describe adverse effects such as headache/pain (26\%), nausea/vomiting (9\%), dizziness (2\%), and other reactions $(<0.1 \%) .{ }^{26}$ Other more recent studies of myelography with iodinated contrast have demonstrated lower rates of adverse effects, ranging from $7.4 \%$ to $14 \% .{ }^{14,15}$ This discrepancy can probably be at least partially accounted for by differences in patient populations, with other studies focusing on myelography for lumbar spinal stenosis and disc herniation, while our patient population included patients with SIH who demonstrated similar symptoms at baseline with known derangement of CSF volumes.

Most important for our study, despite injecting at least the maximum daily recommended intrathecal dose of Omnipaque 300 or 240 twice within a 24 -hour interval, no significant differences were noted in the rate of minor adverse effects between day 1 and day 2 of the procedural pairs. This suggests that there is no accumulative toxicity from subsequent-day intrathecal contrast injections. Because of the low overall systemic dose of iodinated contrast and the relative health of this patient cohort, pre- and postprocedural renal function was not recorded. In patients with renal impairment or renal failure, it may be advisable to adjust contrast dosing or forgo the procedure altogether. However, we suspect that equilibration of the relatively small volume of water-soluble contrast from the CSF to the systemic circulation would presumably limit any increase in CNS toxicity related to delayed renal excretion. ${ }^{23}$ Also, we did not routinely screen for seizure-threshold-lowering medications before performing the procedures, a practice that may further reduce the risk of seizures. ${ }^{27}$

Most interesting, a statistically significant correlation was noted between the volume of intrathecal injectate and transient minor neurologic effects such as vertigo, syncope, altered mental status, and autonomic dysfunction. Specifically, variable amounts of saline injectate were sometimes used to prepressurize the thecal sac in these patients with chronically low CSF volume, which may have resulted in vasovagal reactions or mechanical effects on pain-sensitive nerves and vessels related to CSF pressurization. This effect did not appear to result in any lasting neurologic sequelae. Contrast volumes were relatively constant but were included in the mean injectate calculations because they did constitute a large component of the total injectate volume. Griauzde et $\mathrm{al}^{22}$ also reported transient neurologic symptoms in their experience with intrathecal preservative-free normal saline challenge in patients with $\mathrm{SIH}$. However, their injection rate was reported at $1 \mathrm{~mL} / \mathrm{min}$ in contrast to our fast injection rate of $1 \mathrm{~mL} / \mathrm{s}$, and even higher average volumes of saline were injected in their study $(75.8 \mathrm{~mL})$. Although the sample size of our study is too small to fully characterize the relationship between injectate rate/volume and neurologic symptoms and no true control group was present, our results suggest that standardizing and reducing the volume of intrathecal injectate might be considered to help reduce patient discomfort.

No acute radiation injury occurred, and the average cumulative fluoroscopic skin dose from each procedural pair was comparable with doses seen with common diagnostic visceral and cerebral angiographic procedures. ${ }^{28}$ Medical radiation exposure should always be minimized when possible, and these examinations would certainly not be considered the first-line examination for localization of spinal CSF leaks, given a cumulative dose of 2 DSMs and 2 entire spine CT examinations. However, in the case of patients with SIH with debilitating symptoms and multiple prior nondiagnostic radiographic examinations, a thorough bilateral decubitus DSM examination could be considered.

There are several limitations of this study, most notably its retrospective nature. The sample size is too small to adequately assess certain rare serious adverse effects related to parenteral iodinated contrast exposure such as seizure, coma, or death, which have an expected incidence of $<0.01 \%{ }^{26}$ Additionally, the postprocedural effects of moderate and general anesthesia could account for some of the patients' recorded symptoms as well as mask other symptoms. Other factors potentially contributing to adverse effects could include the needle gauge, orientation of needle bevel during insertion, and stylet use. ${ }^{29-31}$ All 7 patients categorized as having minor neurologic transient effects underwent lumbar puncture with 20-ga rather than 22-ga needles, and it is unclear whether this association is clinically significant, given the lack of similar correlation for pain or nausea. The difference in the injection flow rate is one possibility, but the flow rate differences due to needle gauge would be small. Although preservativefree normal saline has been safely used intrathecally, its hypertonicity relative to the CSF could play a role in adverse symptoms, and further studies comparing the use of artificial CSF (Elliotts B solution; Baxter Laboratories) with saline would be helpful. Finally, opening CSF pressures were not recorded before saline or contrast injection, and variations in the baseline CSF pressure could serve as a confounding factor in the development of minor adverse effects.

Our results are pertinent to a unique group of patients with $\mathrm{SIH}$ and may be of limited generalizability for other types of myelography. A core group of 10 fellowship-trained neuroradiologists who specialize in spine intervention performed the lateral decubitus DSM procedures, and all received training from a single individual. The specialty training of these interventionalists may result in lower adverse effect rates, reducing generalizability of our results. 


\section{CONCLUSIONS}

In patients with SIH without evidence of spinal CSF leak on conventional imaging, consecutive-day lateral decubitus DSM procedures have demonstrated an acceptable risk profile in our 13month experience, and there is no evidence of an increased neurotoxic effect from the cumulative intrathecal contrast dose. Adverse effect rates are comparable with those previously reported for general myelography studies. Increasing volumes of total intrathecal injectate, mostly attributable to prepressurization with saline, may have a correlation with the incidence of transient minor neurologic effects such as syncope, vertigo, autonomic dysfunction, and altered mental status. In patients who are undergoing this procedure with moderate sedation or local anesthesia only, decreasing the volume of injectate could help in reducing patient discomfort. Careful patient selection is warranted, given the cumulative radiation exposure associated with this technique.

\section{REFERENCES}

1. Davidson B, Nassiri F, Mansouri A, et al. Spontaneous intracranial hypotension: a review and introduction of an algorithm for management. World Neurosurg 2017;101:343-49 CrossRef Medline

2. Mokri B. Spontaneous low pressure, low CSF volume headaches: spontaneous CSF leaks. Headache 2013;53:1034-53 CrossRef Medline

3. Akbar JJ, Luetmer PH, Schwartz KM, et al. The role of MR myelography with intrathecal gadolinium in localization of spinal CSF leaks in patients with spontaneous intracranial hypotension. AJNR Am J Neuroradiol 2012;33:535-40 CrossRef Medline

4. Wang YF, Lirng JF, Fuh JL, et al. Heavily T2-weighted MR myelography vs CT myelography in spontaneous intracranial hypotension. Neurology 2009;73:1892-98 CrossRef Medline

5. Farb RI, Nicholson PJ, Peng PW, et al. Spontaneous intracranial hypotension: a systematic imaging approach for CSF leak localization and management based on MRI and digital subtraction myelography. AJNR Am J Neuroradiol 2019;40:745-53 CrossRef Medline

6. Clark MS, Diehn FE, Verdoorn JT, et al. Prevalence of hyperdense paraspinal vein sign in patients with spontaneous intracranial hypotension without dural CSF leak on standard CT myelography. Diagn Interv Radiol 2018;24:54-59 CrossRef Medline

7. Schievink WI, Maya MM, Jean-Pierre S, et al. A classification system of spontaneous spinal CSF leaks. Neurology 2016;87:673-79 CrossRef Medline

8. Schievink WI. Novel neuroimaging modalities in the evaluation of spontaneous cerebrospinal fluid leaks. Curr Neurol Neurosci Rep 2013;13:358 CrossRef Medline

9. Hoxworth JM, Trentman TL, Kotsenas AL, et al. The role of digital subtraction myelography in the diagnosis and localization of spontaneous spinal CSF leaks. AJR Am J Roentgenol 2012;199:64953 CrossRef Medline

10. Hoxworth JM, Patel AC, Bosch EP, et al. Localization of a rapid CSF leak with digital subtraction myelography. AJNR Am J Neuroradiol 2009;30:516-19 CrossRef Medline

11. Luetmer PH, Mokri B. Dynamic CT myelography: a technique for localizing high-flow spinal cerebrospinal fluid leaks. AJNR Am J Neuroradiol 2003;24:1711-14 Medline
12. Schievink WI, Moser FG, Maya MM, et al. Digital subtraction myelography for the identification of spontaneous spinal CSF-venous fistulas. J Neurosurg Spine 2016;24:960-64 CrossRef Medline

13. Schievink WI, Maya MM, Moser FG, et al. Lateral decubitus digital subtraction myelography to identify spinal CSF-venous fistulas in spontaneous intracranial hypotension. J Neurosurg Spine 2019 Sept 13. [Epub ahead of print] CrossRef Medline

14. Matsumoto T, Imagama S, Inoue $\mathrm{H}$, et al. Outpatient myelography: a prospective trial comparing complications after myelography between outpatients and inpatients in Japan. Asian Spine J 2015;9:928-34 CrossRef Medline

15. Albrecht A, Golebiowski M, Kornienko VN, et al. A double-blind, prospective, randomized, multicenter group comparison study of iopromide 240 vs iohexol 240 in myelography. Eur Radiol 1999;9:1901-08 CrossRef Medline

16. Wang $\mathrm{H}$, Binet EF, Gabrielsen TO, et al. Lumbar myelography with iohexol in outpatients: prospective multicenter evaluation of safety. Radiology 1989;173:239-42 CrossRef Medline

17. Sand T, Myhr G, Stovner LJ, et al. Side effects after ambulatory lumbar iohexol myelography. Neuroradiology 1989;31:49-54 CrossRef Medline

18. Kieffer SA, Binet EF, Davis DO, et al. Lumbar myelography with iohexol and metrizamide: a comparative multicenter prospective study. Radiology 1984;151:665-70 CrossRef Medline

19. Eldevik OP, Nakstad P, Kendall BE, et al. Iohexol in lumbar myelography: preliminary results from an open, noncomparative multicenter clinical study. AJNR Am J Neuroradiol 1983;4:299-301 Medline

20. Kim DK, Brinjikji W, Morris PP, et al. Lateral decubitus digital subtraction myelography: tips, tricks, and pitfalls. AJNR Am J Neuroradiol 2020;41:21-28 CrossRef Medline

21. Gatica-Moris SR, Welch TL, Abcejo AS, et al. Anesthesia during positive-pressure myelogram: a new role for cerebral oximetry. $J$ Neurosurg Anesthesiol 2019 Oct 23. [Epub ahead of print] CrossRef Medline

22. Griauzde J, Gemmete JJ, Pandey AS, et al. Intrathecal preservativefree normal saline challenge magnetic resonance myelography for the identification of cerebrospinal fluid leaks in spontaneous intracranial hypotension. J Neurosurg 2015;123:732-36 CrossRef Medline

23. Junck L, Marshall WH. Neurotoxicity of radiological contrast agents. Ann Neurol 1983;13:469-84 CrossRef Medline

24. Skalpe IO, Nakstad P. Myelography with iohexol (Omnipaque); a clinical report with special reference to the adverse effects. Neuroradiology 1988;30:169-74 CrossRef Medline

25. Laasonen EM. Iohexol and metrizamide in lumbar myelography: comparison of side effects. Acta Radiol Diagn (Stockh) 1985;26:76165 CrossRef Medline

26. Omnipaque [package insert]. GE Healthcare, Marlborough, MA; 2018

27. Shah LM, Kranz PG, Anzai Y, et al. Critical assessment of myelography practices: a call for rational guideline revision. AJNR Am J Neuroradiol 2018;39:2378-84 CrossRef Medline

28. Mahesh M. Fluoroscopy: patient radiation exposure issues. Radiographics 2001;21:1033-45 CrossRef Medline

29. Strupp M, Brandt T, Müller A. Incidence of post-lumbar puncture syndrome reduced by reinserting the stylet: a randomized prospective study of $\mathbf{6 0 0}$ patients. J Neurol 1998;245:589-92 CrossRef Medline

30. Halpern S, Preston R. Postdural puncture headache and spinal needle design: meta-analyses. Anesthesiology 1994;81:1376-83 CrossRef Medline

31. Norris MC, Leighton BL, DeSimone CA. Needle bevel direction and headache after inadvertent dural puncture. Anesthesiology 1989;70:729-31 CrossRef Medline 